\title{
Wollastonite-Based Chemically Bonded Phosphate Ceramic Composites
}

\author{
Henry A. Colorado ${ }^{1,2}$, Clem Hiel ${ }^{3,4}$, Thomas Hahn ${ }^{1}$ and Jenn Ming Yang ${ }^{1}$ \\ ${ }^{1}$ University of California Los Angeles, Materials Science and Engineering \\ 2Universidad de Antioquia, Mechanical Engineering \\ ${ }^{3}$ Composites Support and Solutions \\ ${ }^{4} \mathrm{MEMC}$-University of Brussels (VUB) \\ 1,3 United States \\ ${ }^{2}$ Colombia \\ ${ }^{4}$ Belgium
}

\section{Introduction}

Chemically Bonded Ceramics (CBCs) have been extensively used many applications. These include: radiation shielding systems, nuclear waste solidification and encapsulation; high temperature structural applications; composites and biomedical applications. The objective of this chapter is to present the science, manufacturing and mechanical properties of the Wollastonite $\left(\mathrm{CaSiO}_{3}\right)$ based Chemically Bonded Phosphate Ceramics (Wo-CBPCs) composites, Fig. 1. In general, the CBPCs belong to the broader field of Chemically Bonded Ceramics (Della Roy, 1987; Jeong \& Wagh, 2002; Wagh, 2004) where the name CBPC refers to ceramic materials that reach their final mechanical properties by chemical reactions at low temperatures (typically less than $300^{\circ} \mathrm{C}$ ) instead of the high temperature processing (by thermal diffusion or melting) as is normally done in traditional ceramics and cements. The Wo-CBPCs are composite materials themselves, they belong to Chemical Bonded Ceramics (CBCs) consolidated by an acid base reaction (Wilson \& Nicholson, 1993). Wo-CBPCs are multiphase materials with silica, Wollastonite and brushite grains in a matrix of amorphous calcium phosphates. Reinfocing materials such as graphite nanoplateles, glass fibers and carbon fibers have been successfully incorporated into - CBPCs, realizing high performance composites.

\subsection{Wo-CBPCs and traditional cements}

The manufacturing of CBPCs and Portland cement concrete has some similarities. In Portland cement concrete water, clinker and aggregates are used to consolidate the concrete, in CBPCs an acid formulation and a metallic oxide are mixed to fabricate the ceramic. In particular, for Wo-CBPC, a phosphoric acid formulation and Wollastonite powder are the main raw materials. However, there are several important advantages of using CBPCs as opposed to cements. Among them are better mechanical properties (compressive and flexural strength), lower density, ultra fast (controllable) setting time, and an environmentally benign process. Although cements are usually made at room temperature, 
clinker is processed at very high temperature (about $1450^{\circ} \mathrm{C}$ ). It is well known that between 900 and $1100 \mathrm{~kg}$ of $\mathrm{CO}_{2}$ is emitted for every $1000 \mathrm{~kg}$ of Portland cement produced in the U.S. This quantity depends on the fuel type, raw ingredients used and the energy efficiency of the cement plant (EPA, 2005). Juxtaposed the Wo-CBPCs process is all performed at room temperature but other CBPCs, like traditional cements, may include high temperature processing of the raw materials (Wagh, 2004).

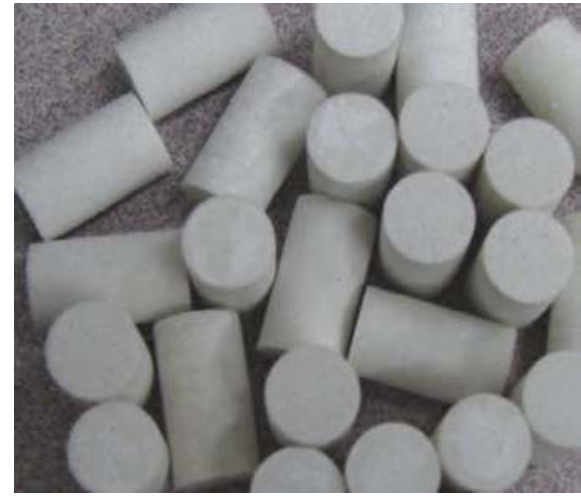

a

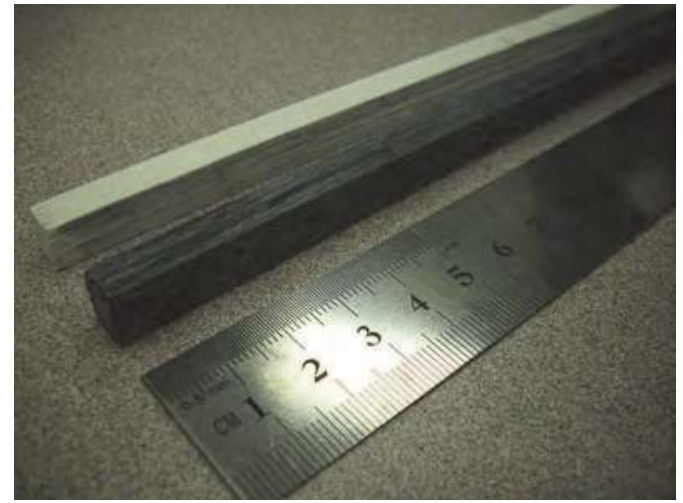

b

Fig. 1. Wollastonite-based CBPCs, a) compression samples, b) pultruded bars of CBPCs reinforced with glass fibers (white) and with carbon fibers (black).

Fig. 2 illustrates the advantage of CBPCs compared Portland cement concrete. In ceramics and cements, the density has an important role in the mechanical response of the material. For Wo-CBPC it has been found that (Colorado et al., 2010a; 2010c) the porosity can be controlled by changing the mixing parameters. Changing the porosity is a way to change the density. It has been observed in CBPCs that density typically varies to values from 1.9 to 2.4 $\mathrm{g} / \mathrm{cm}^{3}$. This produces a variation in the compressive strength typically from 60 to $130 \mathrm{MPa}$ (Colorado et al., 2010b). Similarly, Portland cement concrete has a density that typically ranges from 3 to $3.5 \mathrm{~g} / \mathrm{cm}^{3}$ which produces a variation in the compressive strength typically from 30 to $40 \mathrm{MPa}$. When these values are plotted as compressive strength over the density, we can see that Wo-CBPCs, and in general other CBPCs (it is possible to obtain pretty similar values), have superior advantages for applications of high strength and low density, in addition to the fabrication process. Then, CBPCs fill a gap between cements and ceramics. In particular, Wo-CBPCs have been developed for structural applications including fire environments (Colorado et al., 2010a). Sections below will present this material in detail as well as some of these applications.

The bonding in CBPCs is a mixture of ionic, covalent, and van der Waals bonding, with the ionic and covalent dominating; unlike in traditional cement hydration products, in which van der Waals and hydrogen bonding dominate. CBPCs can reach a compressive strength of $100 \mathrm{MPa}$ in minutes, which can be controlled with additives and processing as will be presented later, whereas Portland cement based concrete reaches a compressive strength of about 20Mpa after 28 days. Furthermore, CBPCs do not require aggregates, which is important for applications where light weight is required. CBPCs density can range between 1.8 and $2.5 \mathrm{~g} / \mathrm{cm}^{3}$, which is particularly interesting when compared with Portland cement, 
for which in excess of $3.3 \mathrm{~g} / \mathrm{cm}^{3}$. Even lower density values have been reported for other CBPCs.

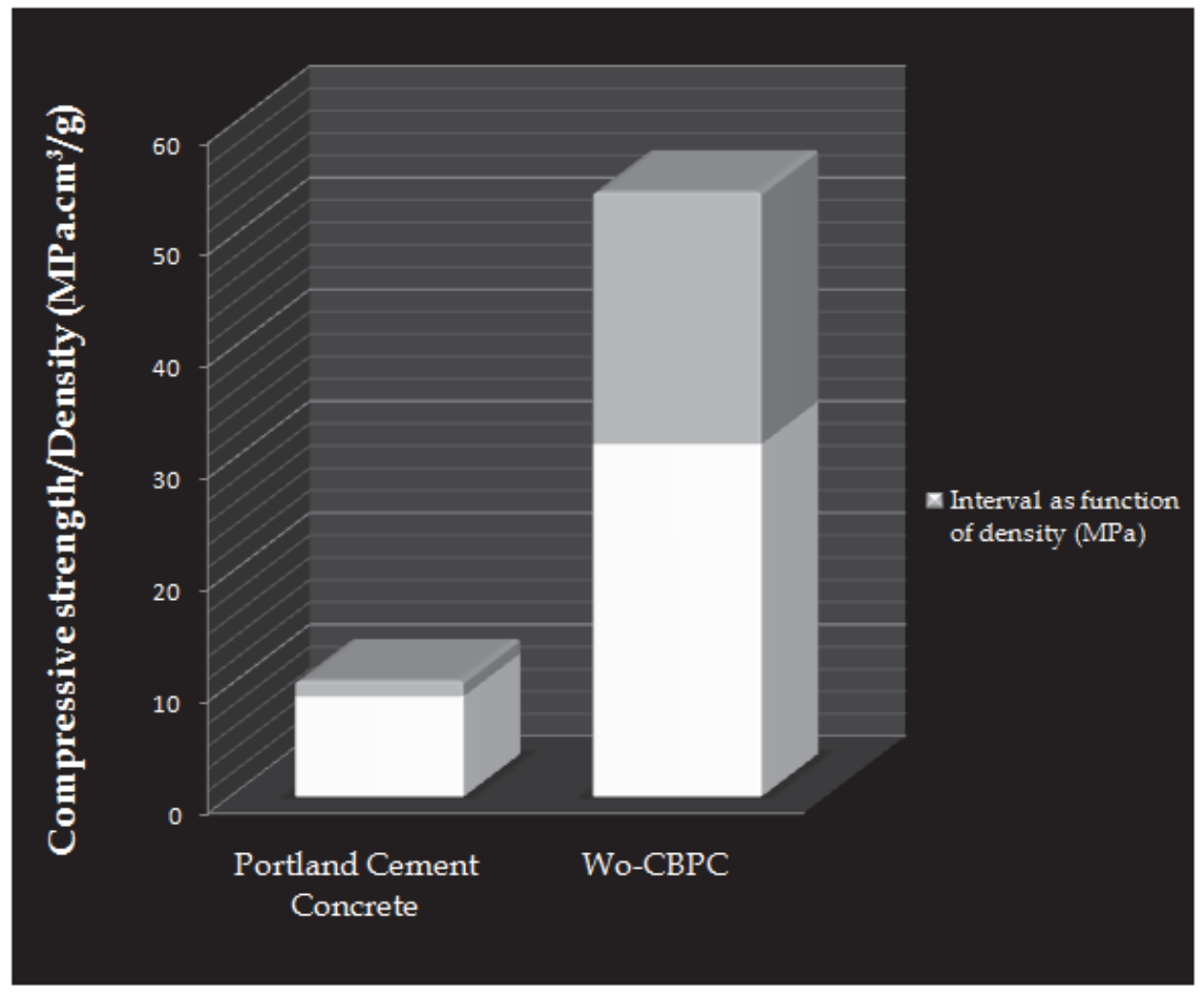

Fig. 2. Comparison of the ratio compressive strength over the density for Portland cement concrete and CBPCs.

Also, $\mathrm{pH}$ is an important factor for manufacturing of composite materials. We found that ratios of phosphoric acid to Wollastonite between 1.0 and 1.2 leads into a neutral product, with a $\mathrm{pH}$ of 7.0. This is particularly interesting when they are compared with Portland cement for which $\mathrm{pH}$ is in excess of 12, which does not allow the use of E-glass fibers as a reinforcement. The neutral $\mathrm{pH}$ is very convenient when either particles, fibers or any other reinforcements are introduced in the CBPCs. This opens up many applications related to infrastructure repair such as roads, bridges and pipes.

On the other hand, the $\mathrm{pH}$ can be controlled out of this range by putting more or less acidic solution, open applications in which a strong reaction is required. CBPCs can be used to encapsulate nuclear waste. There are several solutions for treatment of nuclear wastes, however, CBPCs are unique due that can set very fast minimizing the risk of contamination and irradiation, process can be conducted at room temperature (better when compare with a glass encapsulation in which manufacturing involves high temperature, which can leads in evaporation of hazardous materials), and $\mathrm{pH}$ can be controlled easily. By using different acids, oxides and adding different additives, different efficient materials for structural and shielding applications can be fabricated. 
The chemical processing in $C B C^{\prime}$ s allows them to be inexpensive in high volume production. Therefore CBCs are environmentally benign and fill the gap between cements and ceramics. The fabrication of conventional cements and ceramics involve energy consuming high temperature processes, which adversely affect the environment.

The sections below will present the manufacturing and science of the CBPCs with different reinforcements.

\subsection{Structure formation of Wo-CBPCs}

The CBPCs form by acid-base reactions between an acid phosphate and Wollastonite. This reaction is exothermic. When the phosphoric acid formulation and the Wollastonite powder mixture are stirred, the sparsely alkaline oxides dissolve and an acid base reaction is initiated. The result is a slurry that hardens in a ceramic product. The setting is the result of gelation by salt formation and the $\mathrm{Ca}^{+2}$ cations are extracted from the calcium silicate. Then, we have two main process involved, the release of cations from the Wollastonite and the interaction with the acidic solution. Details of this proposed mechanism of formation have been extended presented (Wagh \& Jeong 2003a, 2003b and 2003c; Wagh, 2004).

When powders of metal oxides (for Wo-CBPC is $\mathrm{CaSiO}_{3}$ ) are stirred in solvent such as an acid-phosphate solution (For Wo-CBPC is $\mathrm{H}_{3} \mathrm{PO}_{4}$ ), they dissolve slowly in the solvent and release cations (For Wo-CBPC are Calcium cations) in the acidic solution. These cations react with the phosphate anions within the solvent and form a precipitate of salt molecules.

Under the right conditions mainly controlled by the $\mathrm{pH}$ (in Wollastonite and phosphoric acid, the Wo-CBPC can be consolidated over a wide range of $\mathrm{pH}$ ), these molecules form an ordered structure that grows into crystals that conform the CBPC. Thus, CBPC formation is a result of the following three steps (Wagh, 2004):

a. The acid phosphates dissolve in water, release phosphate anions, and form an acidphosphate solution of low $\mathrm{pH}$.

b. The oxides dissolve gradually in the low $\mathrm{pH}$ solution and release cations.

c. The phosphate anions react with the newly released cations and form a coordinated network and consolidate into a CBPC.

Several equations for the products when mixing Wollastonite with phosphoric acid have been proposed (Mosselmans et al., 2007) for molar ratios $r$ of the phosphoric acid to Wollastonite powder between 0.39 and 1.66. For $r$ between 0.39 and 1, only one type of calcium phosphate (brushite) is formed. The formation reaction of brushite $\left(\mathrm{CaHPO}_{4} \cdot 2 \mathrm{H}_{2} \mathrm{O}\right)$ is represented in Eq. (1).

$$
\mathrm{CaSiO}_{3}+\mathrm{H}_{3} \mathrm{PO}_{4}+(1+\mathrm{x}) \mathrm{H}_{2} \mathrm{O}=\mathrm{SiO}_{2} \cdot \mathrm{xH}_{2} \mathrm{O}+\mathrm{CaHPO}_{4} \cdot 2 \mathrm{H}_{2} \mathrm{O}
$$

For $r$ between 1 and 1.66, three different calcium phosphates (brushite, monetite and calcium dihydrogenphosphate monohydrate) can be formed, depending on the molar ratio $r$. The reactions leading to monetite $\left(\mathrm{CaHPO}_{4}\right)$ and calcium dihydrogenphosphate monohydrate $\left(\mathrm{Ca}\left(\mathrm{H}_{2} \mathrm{PO}_{4}\right)_{2} \cdot \mathrm{H} 2 \mathrm{O}\right)$ are depicted in Eqs (2) and (3), respectively.

$$
\begin{gathered}
\mathrm{CaSiO}_{3}+\mathrm{H}_{3} \mathrm{PO}_{4}=\mathrm{SiO}_{2} \cdot \mathrm{yH}_{2} \mathrm{O}+\mathrm{CaHPO}_{4}+(1-\mathrm{y}) \mathrm{H}_{2} \mathrm{O} \\
\mathrm{CaSiO}_{3}+2 \mathrm{H}_{3} \mathrm{PO}_{4}+\mathrm{zH}_{2} \mathrm{O}=\mathrm{SiO}_{2} \cdot \mathrm{zH}_{2} \mathrm{O}+\mathrm{Ca}\left(\mathrm{H}_{2} \mathrm{PO}_{4}\right)_{2} \cdot \mathrm{H}_{2} \mathrm{O}
\end{gathered}
$$

It has been found that a ratio of an special phosphoric acid formulation to Wollastonite powder between 1.0 and 1.2 leads into a neutral product, with a $\mathrm{pH}$ of 7.0 (Colorado et al., 2010b). 


\section{Case of study: Wollastonite-based CBPCs}

\subsection{Raw materials}

The Wo-based CBPCs are fabricated with Wollastonite (Calcium silicate, $\mathrm{CaSiO}_{3}$ ) powders and a phosphoric acid formulation. Wollastonite is a mineral with a triclinic structure. It is usually white and may contain small amounts of iron, magnesium, and manganese substituting for calcium. There are many industrial applications for Wollastonite. These include reinforcements for structural ceramics products like bricks and pipes; filler for paintings with improved resistant to environment; filler for plastics. Typical Wollastonite powders used in structural applications are showed in Table 1 (from NYCO). These have mean size distribution ranging from 3.5 to $15 \mu \mathrm{m}$.

\begin{tabular}{|l|l|l|l|}
\hline $\begin{array}{l}\text { Powder } \\
\text { reference }\end{array}$ & $\begin{array}{l}\text { Mean particle size } \\
(\mu \mathrm{m})\end{array}$ & $\begin{array}{l}\text { Surface Area }\left(\mathrm{m}^{2} / \mathrm{g}\right) \\
(\mathrm{BET})\end{array}$ & Moisture $(\%)$ \\
\hline M200 & 15 & 1.1 & 0.05 \\
\hline M325 & 10 & 1.3 & 0.20 \\
\hline M400 & 8 & 1.6 & 0.20 \\
\hline M1250 & 3.5 & 2.9 & 0.25 \\
\hline
\end{tabular}

Table 1. Properties of typical Wollastonite powders as received

On the other hand, Phosphoric acid (H3PO4) also known as orthophosphoric acid, is an inorganic acid used in many applications. These include chemical etching of silicon nitride $\left(\mathrm{Si}_{3} \mathrm{~N}_{4}\right)$ in microfabrication, hydroponics to lower the $\mathrm{pH}$ of nutrient solutions, rolyte in copper electropolishing, high-performance liquid chromatography, ingredient that gives the bite taste in Coca-Cola and Pepsi sodas and additive to stabilize acidic aqueous solutions within a wanted and specified $\mathrm{pH}$ range.

For Wo-CBPCs, the phosphoric acid formulation was prepared in Composites Support and Solutions-CS\&S. Thus, an attenuated phosphoric acid with additives was used in the fabrication of all Wo-CBPCs.

\subsection{Manufacturing}

The fabrication of CBPCs is one of its main advantages when they are compared to traditional ceramics and cements since high temperature processing can be completely annulled in the entire manufacturing.

Mixing process: For mixing the raw materials, a good mixing is needed and several techniques have shown efficiency. The traditional Mechanical Blade Mixing is enough for most of the structural applications. This is the more inexpensive method and it is available everywhere. Also, it is ideal for applications where you need a material with some porosity such as in fire walls or thermal insulation. Another useful method is Resonant Acoustic Mixing (RAM). This method is particularly useful for CBPCs when a dried mixing is a better option. A good mixing of different Wollastonite powder size, particles or short fibers as reinforcement and solid additives have been demonstrated with this method. The RAM is also effective in removing bubbles and pores from the liquid in CBPC manufacturing, which is particularly important for structural applications. Finally, Planetary Centrifugal Mixing is also effective in removing bubbles and pores.

Moulds: Different materials for moulds have been investigated. Polymer based materials like Teflon in combination with inorganic mould release is the best solution. Metals in 
general bond very well to the CBPC which prevent them to be used as mould in most of the cases.

Temperature: in order to extend and control the pot life of the resin, since the reaction is exothermic, cooling the raw materials can help to extend the life for hours.

Aging: Exposing the Wollastonite powder to air also contributes to increase the pot life of the resin. Moisture reduces the reactivity in the powder surface. However, it has been found for that when they are exposed for more than a year, the compression strength of the Wo$\mathrm{CBPC}$ is reduced.

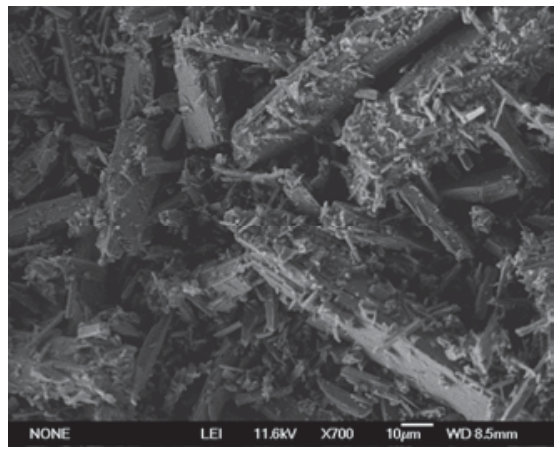

a

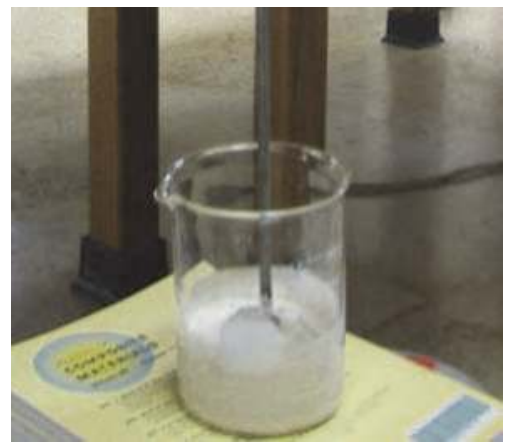

b

Fig. 2. a) Typical Wollastonite, b) blade mixing used for the manufacturing of Wo-CBPCs.

\subsection{Wo-CBPCs and its composite}

The Wo-CBPCs are composite materials itself as confirmed with X Ray Diffraction (XRD) in Fig. 3. Several crystalline (Wollastonite and Brushite) and amorphous phases (silica and amorphous calcium phosphates) are shown. From one highly crystalline mineral (Wollastonie) is obtained a composite material with amorphous and crystalline phases.

In Fig. 4, phases were identified in the SEM-EDAX by X-ray mapping for the cross section of CBPCs. The composition distribution of calcium, silicon and phosphorous is shown in Fig. $4 \mathrm{~b}$, $\mathrm{c}$ and d respectively. Fig. $4 \mathrm{~b}$ shows evidence of some Wollastonite $\left(\mathrm{CaSiO}_{3}\right)$ grains which transformed into silica (by giving up calcium) and some which did not transform. Fig. 4c shows silica glass as well as Wollastonite grains. Fig. $4 \mathrm{~d}$ shows the calcium phosphate matrix. Numbers 1, 2 and 3 correspond to silica, Wollastonite and calcium phosphates respectively.

Fig. 5a shows a general SEM image of the CBPC with microcracks. Smooth zones correspond to silica and Wollastonite (partially or un-reacted) grains.

In some of these silica and Wollastonite grains, interfacial cracks appear. However, most of the cracks grow and propagate in the calcium phosphate matrix until they are eventually stopped by the grains. The silica and remaining Wollastonite particles provide nuclei for crystallization and can act as a second phase that reinforces the matrix. As the drying process occurs, shrinkage and micro crack growth increase.

As a result, interfacial cracks appear in grain interfaces between both silica and Wollastonite grains with the calcium phosphate matrix. A representation of the phenomena is presented in Fig. 5b. The drying process is natural because of the excess water present in the aqueous phosphoric acid formulation. 


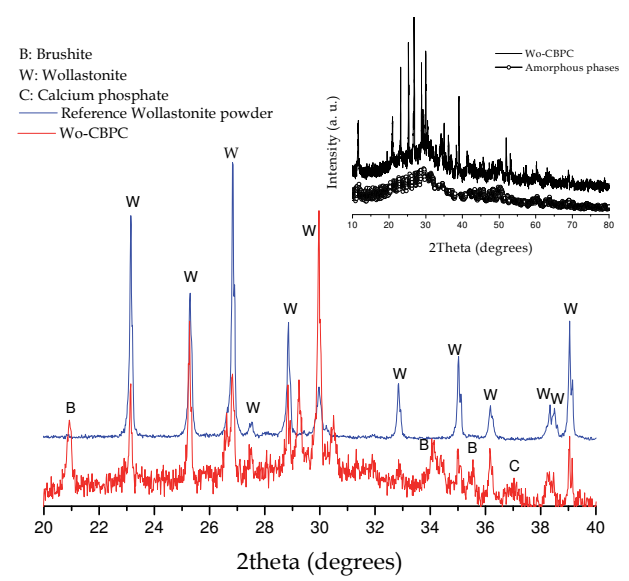

Fig. 3. XRD spectra for the Wo-CBPC, its Wollastonite raw material shown for comparison proposes and a separated plot showing crystalline and amorphous phases in Wo-CBPC.

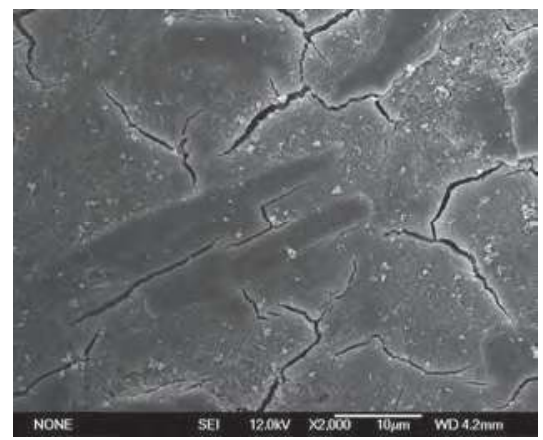

a)

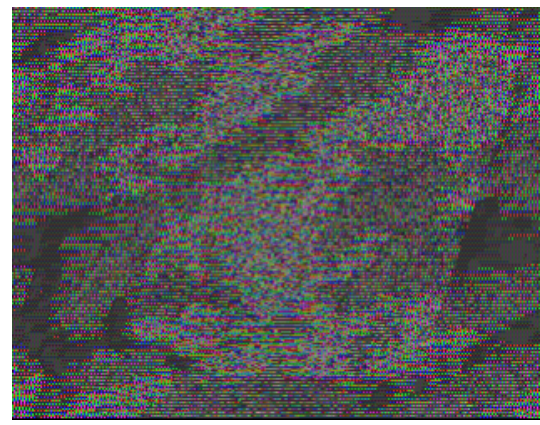

c) Si map

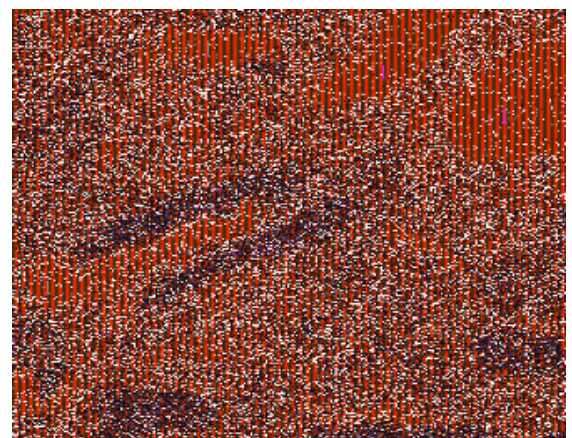

b) Ca map

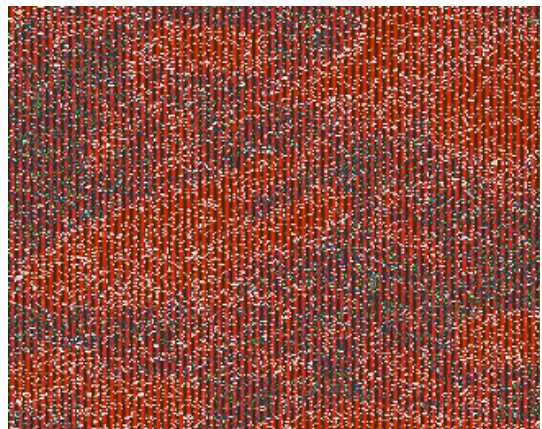

d) $\mathrm{P}$ map

Fig. 4. X-ray maps of pultruded Wo-CBPC, a) topographical image; and b) Ca, c) Si and d) P concentration images. Numbers 1, 2 and 3 correspond to silica, Wollastonite and calcium phosphates respectively. 


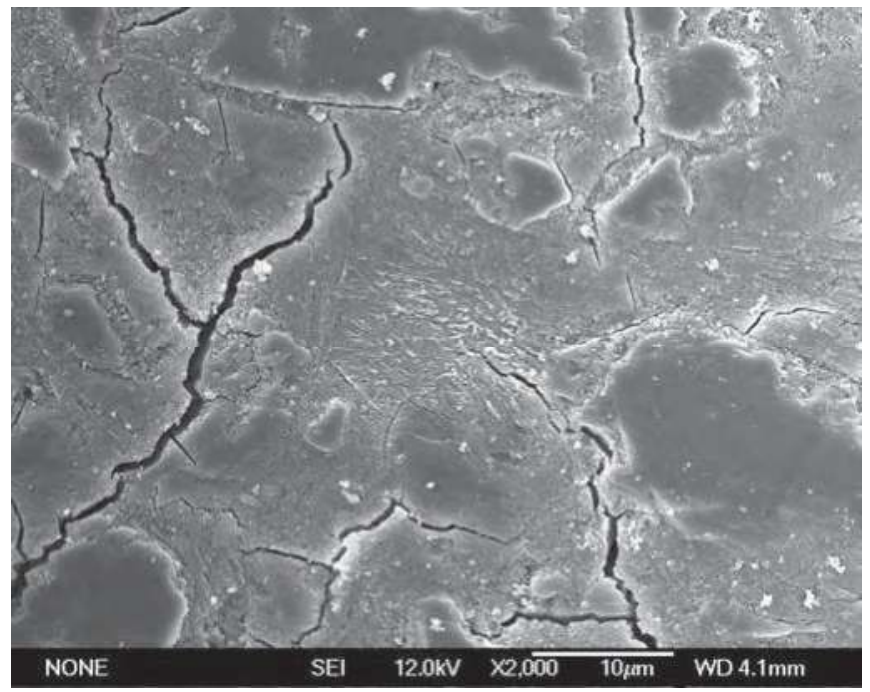

a

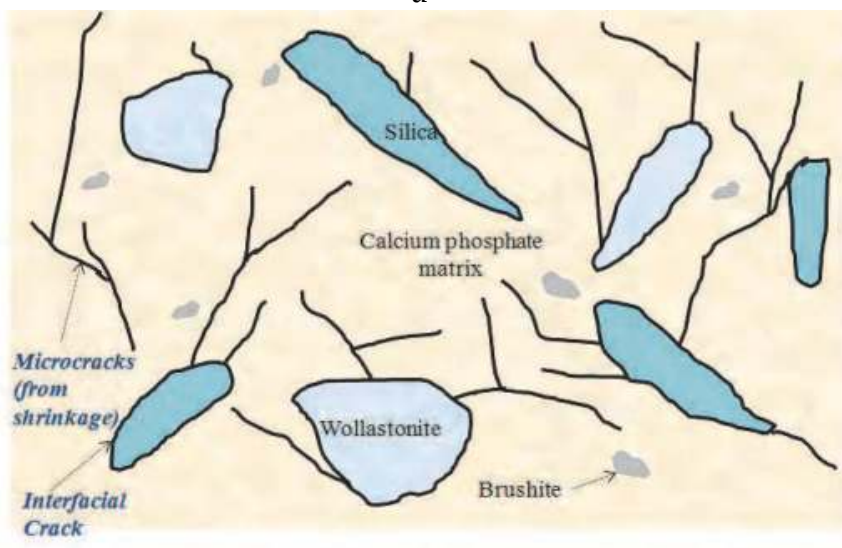

$\mathrm{b}$

Fig. 5. Cross section view a) Wo-CBPC SEM image fabricated with M200 Wollastonite powder, b) representation of the Wo-CBPC before and after the shrinkage process starts.

\subsection{Influence of aging and particle size distribution of wollastonite on the mechanical properties of CBPC}

The compressive strength for the Wo-CBPCs made with new and two years old M200 Wollastonite powders are presented in Fig. 6a. The compressive strength for two year old Wo-CBPC made with M200 is 45\% less than for the baseline material made with two week old M200. This effect has been associated with the moisture effect (Colorado et al., 2010b) on the Wollastonite surface, which decreases its reactivity when it is mixed with the aqueous phosphoric acid formulation.

The compressive strength for the CBPCs made with two years old M200, M400 and M1250 Wollastonite powders are presented in Fig. 6b. As expected, the highest values (not the 
mean) are observed for the small powder sizes (see Table 1). However, the error bars are slightly longer for the small powders sizes, which can be caused by increased porosity due to the high reactivity of the smallest powders. This is an effect of the increase in the surface area. As we explained before, the manufacturing problems associated with the fast reaction and viscosity can be reduced by cooling the raw materials at temperatures below $10^{\circ} \mathrm{C}$. However, Fig. 6 indicates that the M400 particle size distribution creates a maximum compressive strength.

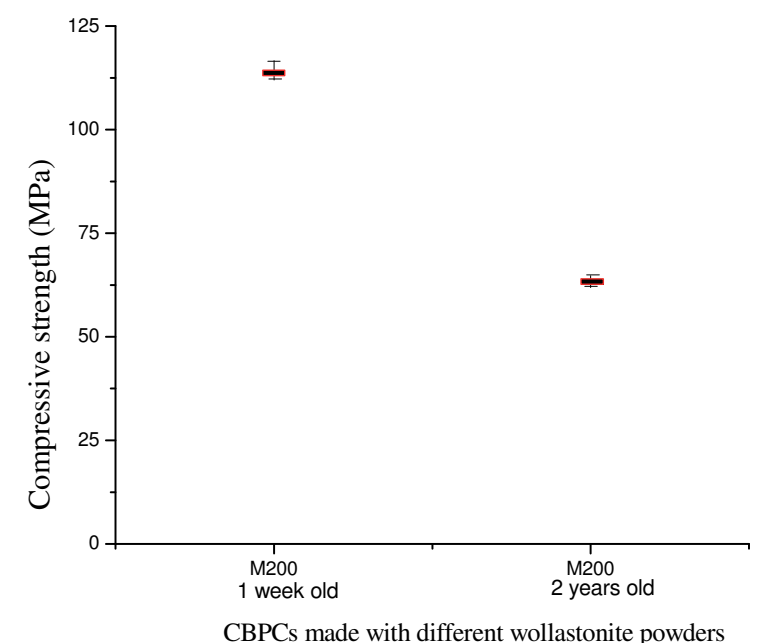

a

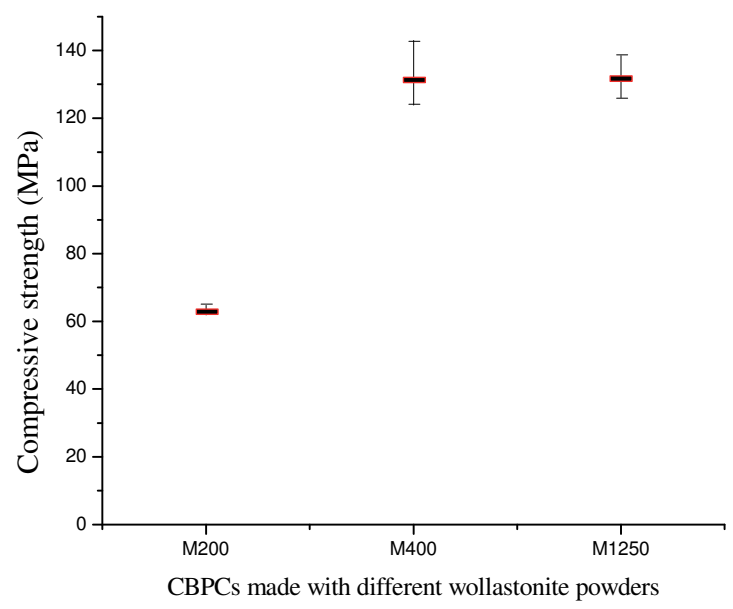

b

Fig. 6. Compressive strength for Wo-CBPCs made with a) M200 2 weeks and 2 years old Wollastonite powder; b) M200, M400 and M1250 Wollastonite powders all 2 years old. 


\section{Wo-CBPC composites for structural applications}

\subsection{Wo-CBPCs reinforced with graphite nanoplatelets (GNPs)}

GNPs have been shown as effective to reinforce Wo-CBPCs matrix composites (Colorado et al, 2011). GNPs are shown in Fig. $7 \mathrm{a}$ and $\mathrm{b}$ respectively. These GNPs have typically a diameter of $1 \mu \mathrm{m}$ and a thickness of $300 \mathrm{~nm}$. Two procedures were followed according to the GNP treatment, illustrated in Fig. 8.

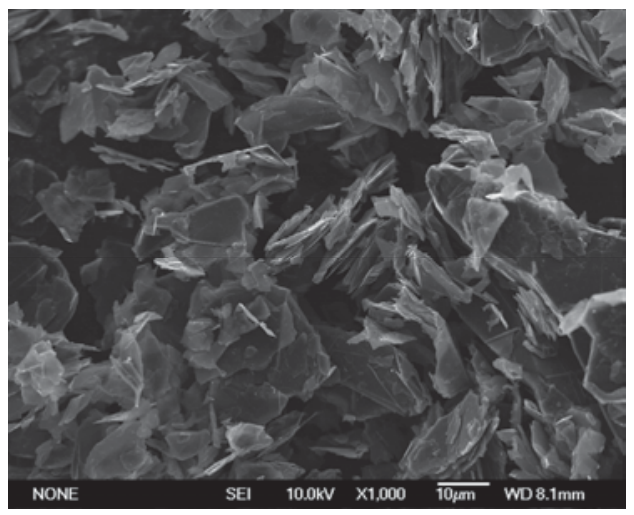

a)

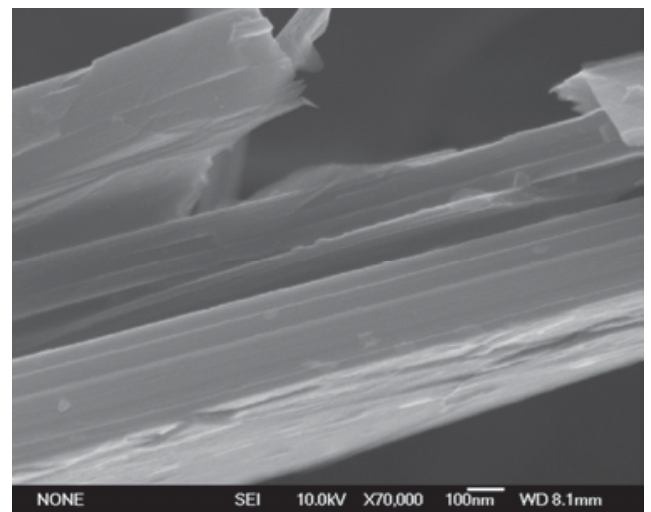

b)

Fig. 7. GNPs, a) group view at low magnification, b) side view at high magnification.

In the first process, GNPs were oxidized in open air at $450^{\circ} \mathrm{C}$ for 2 hours in a Barnstead Thermolyne 1400 furnace, using the method shown in Fig. 8a. A homogeneous mixture of $100 \mathrm{~g}$ of wollastonite powder and $1.0 \mathrm{wt} \%$ of GNPs was obtained in the RAM at $60 \mathrm{~Hz}$ after 5 min of mixing. Then $101 \mathrm{~g}$ of these powders' mixture and $120 \mathrm{~g}$ of the phosphoric acid formulation was kept in a closed container at $5^{\circ} \mathrm{C}$ to prevent water absorption. Then, the same procedure was followed in the Thinky mixer and the corresponding samples preparation.

In the second process, GNPs were functionalized in nitric acid at $115^{\circ} \mathrm{C}$ for 4 hours, using the method shown in Fig. $8 \mathrm{~b}$. Then filtered and $1.0 \mathrm{wt} \%$ of GNPs over the total mixture was mixed with phosphoric acid without washing the remaining nitric acid. It was found in this research that small concentrations of either sulfuric or nitric acid do not change the bending strength in CBPC significantly. Then, the same procedure was followed cooling the liquid and powder and, the mixing in the Thinky mixer and the corresponding samples preparation.

Fig. 9 shows GNPs (treated with nitric acid) reinforced Wo-CBPC matrix composite. The cracks generated in the shrinkage process (see black dashed arrows) were stopped by the GNPs grouped in the wide marked areas. A silica grain (primitive wollastonite powder) is free of cracks. However, cracks are around the entire interface with the matrix and some of them are growing far away, in the opposite direction to the GNPs' zone.

A representation of the Wo-CBPC reinforced with GNPs is shown in Fig. 10. The GNPs contribute to stop crack growing generated in the shrinkage process. Interfacial cracks in the silica and Wollastonite grains are also represented. 


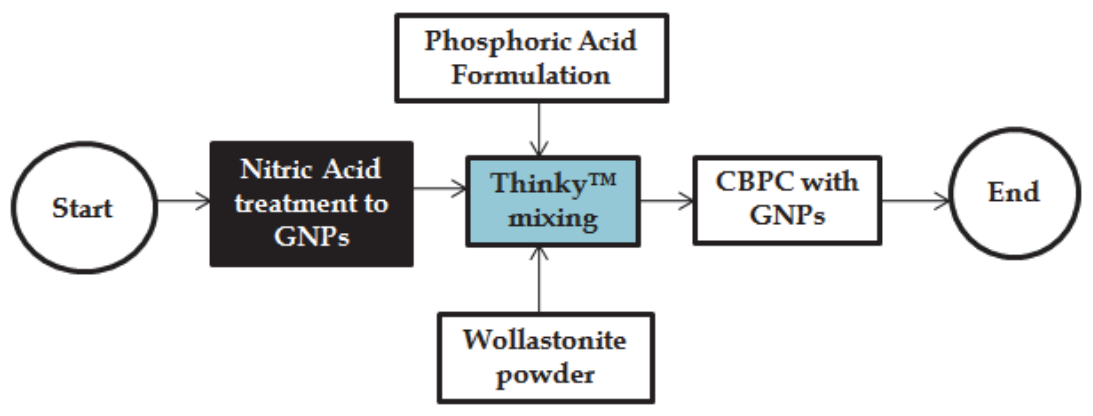

a

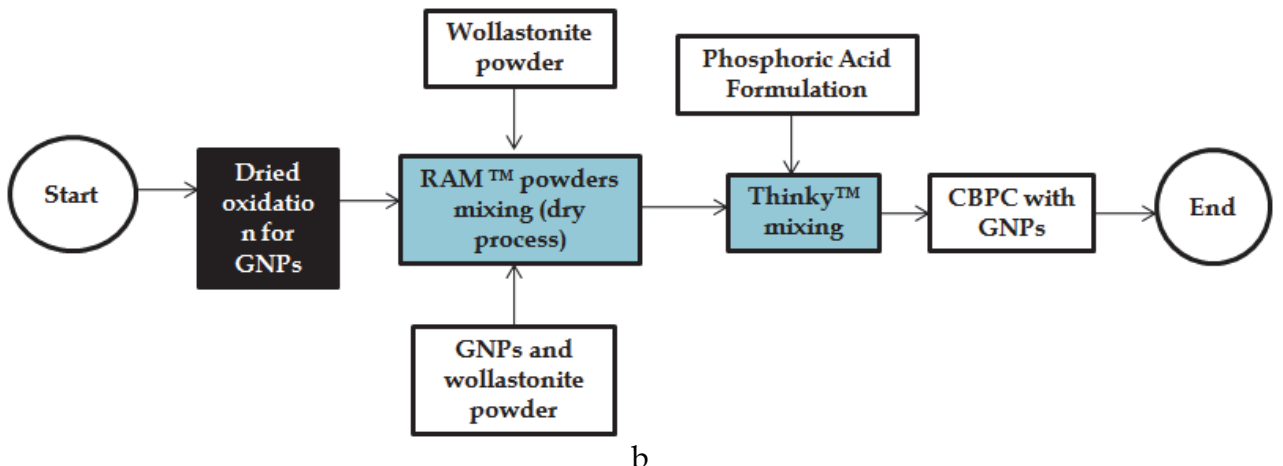

Fig. 8. Simplified flow charts of the processes for functionalize the GNPs, a) procedure using nitric acid, b) procedure using a dried oxidation on air.

The effect of GNPs in the bending strength of Wo-CBPC was investigated by the three point bending test. Results are presented in Fig. 11. A total of 60 samples were tested, 10 samples for the Wo-CBPCs (C-Ref) as reference, 20 samples for Wo-CBPCs with GNPs treated as dried oxidation (C-GNPs in DO), 20 samples for Wo-CBPCs with GNPs functionalized with nitric acid (C-GNPs in NA), and 10 samples of Wo-CBPCs with GNPs as-received (C-GNPs). The span length was $40 \mathrm{~mm}$, the samples dimensions were $90 \times 8.0 \times 6.0 \mathrm{~mm}^{3}$ and the crosshead speed was $2.5 \mathrm{~mm} / \mathrm{min}$. Some samples were tested after drying at room temperature in open air for 5 days, and others after the drying process described above (50C-105-200C).

For all type of samples the bending strength decreased after the drying process. For GNPs oxidized in open air, maximum bending strength and mean for non dried samples were 26.7 and 23.3 MPa respectively. This result is almost three times the bending result from the CBPC. For GNPs functionalized with nitric acid, maximum bending strength and mean for non dried samples were 20.4 and 19.3 MPa respectively. The lower bending strength of CBPC reinforced with GNPs functionalized with nitric acid with respect to the GNPs oxidized in open air is believed related to the presence to a bigger amount of amorphous phases due to the $9.0 \mathrm{wt} \%$ of nitric acid added (over the total mixture), which is a fifth of the acid content in the mixture. 


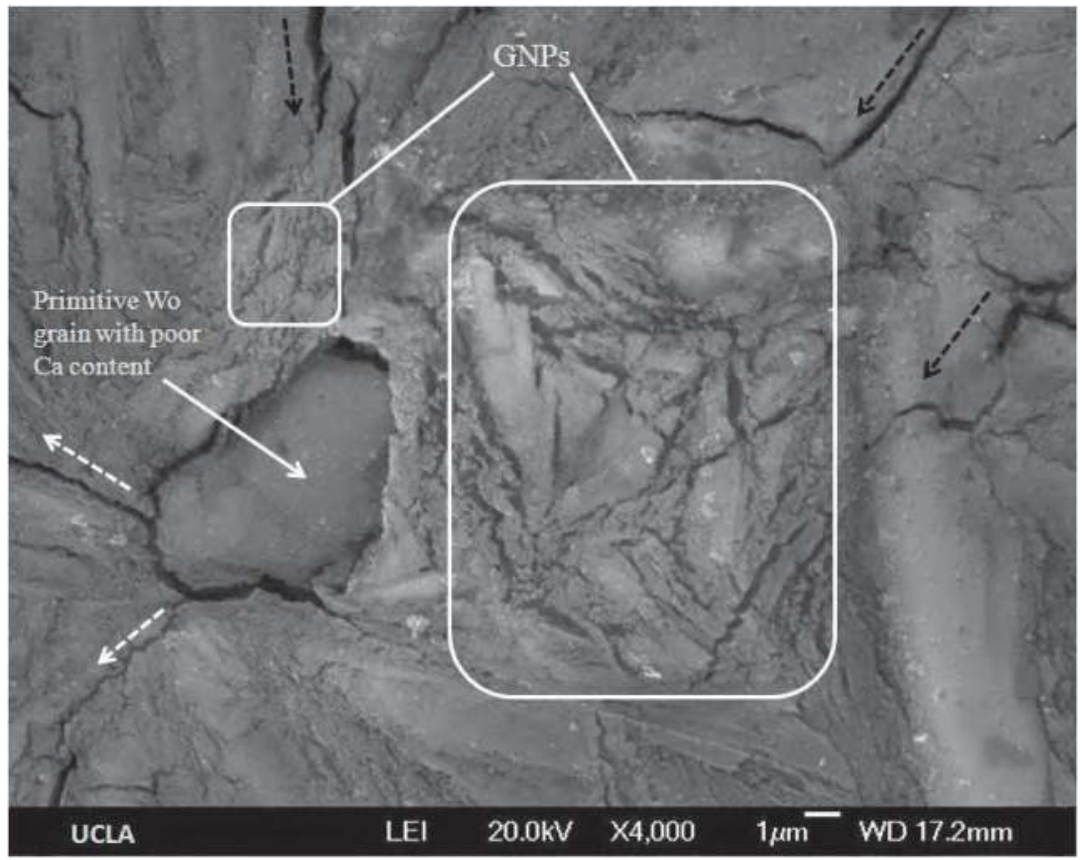

Fig. 9. SEM image of Wo-CBPC reinforced with GNPs showing crack growing stopped due to the GNPs.

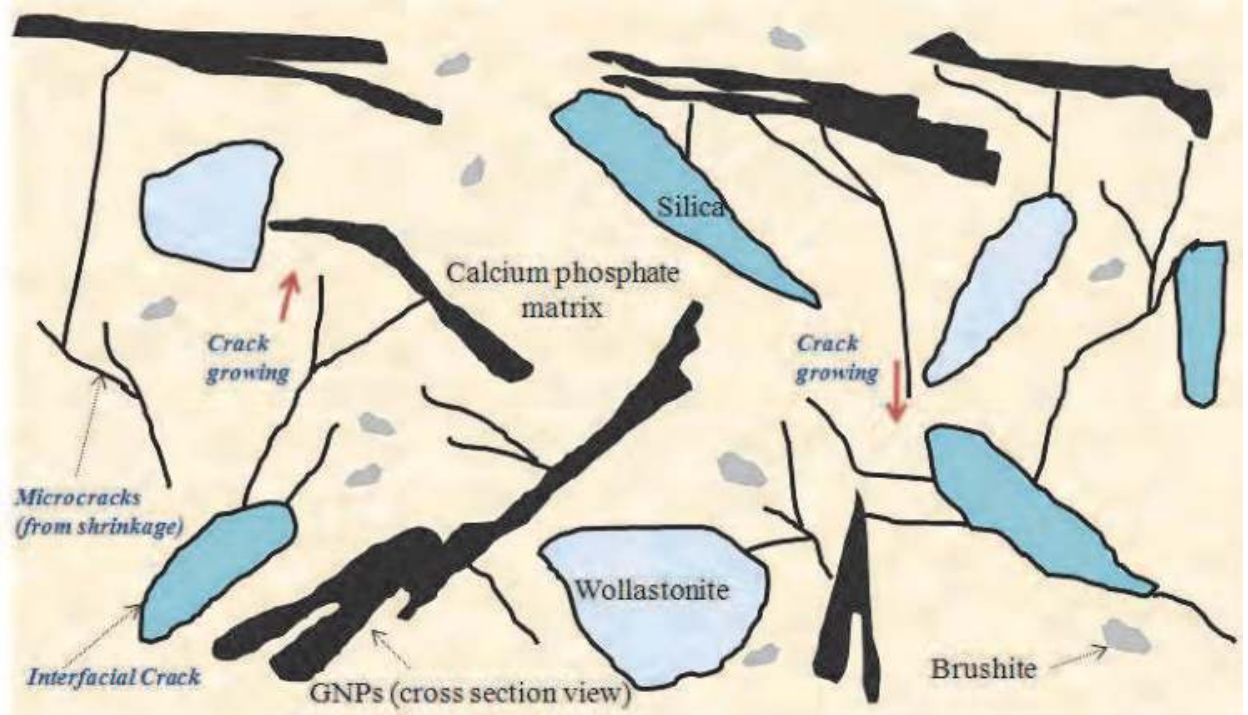

Fig. 10. Cross section view representation of the cracks (generated during the shrinkage process) growing and being stopped by GNPs. 


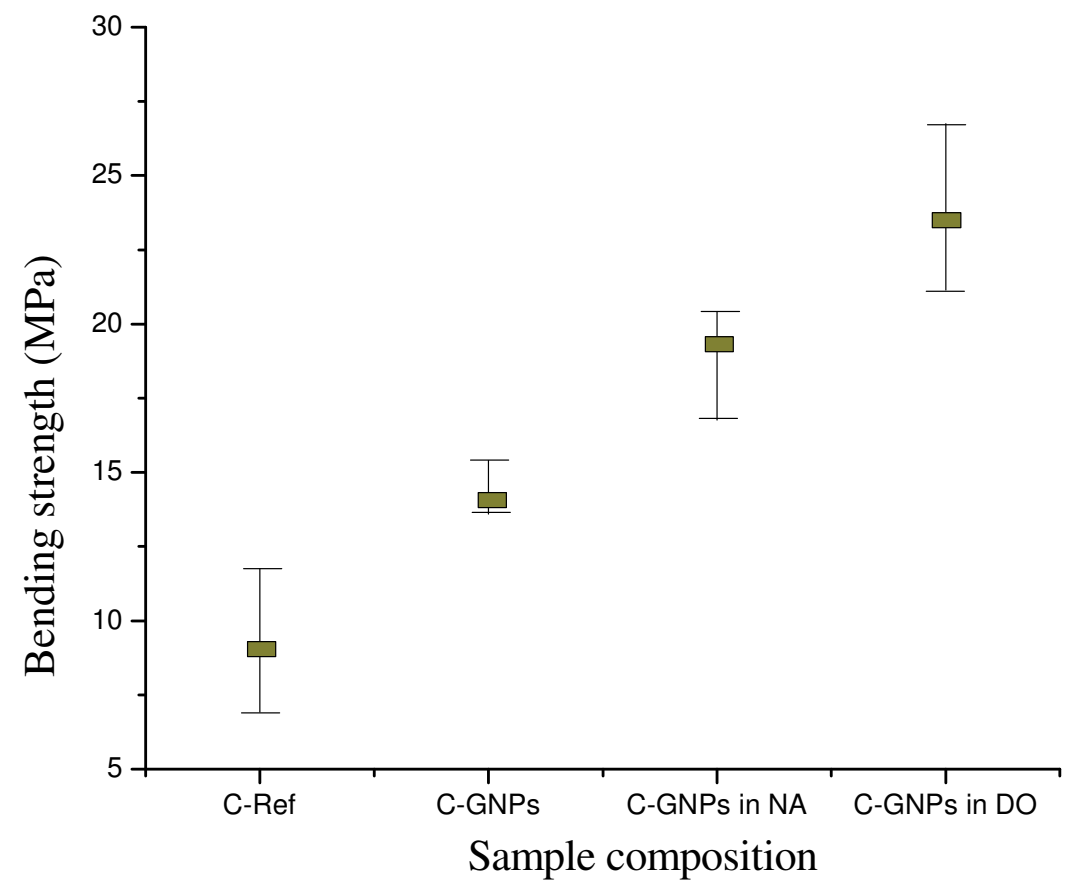

Fig. 11. Three point bending tests for Wo-CBPC and Wo-CBPC with GNPs

\subsection{CBPCs reinforced with continuous fibers fabricated by pultrusion}

For all samples, $120 \mathrm{~g}$ of a phosphoric acid formulation and $100 \mathrm{~g}$ of treated natural wollastonite powder (M325 from CS\&S, see Table 1) were mixed to obtain a 1.2 ratio of liquid/powder. Resonant Acoustic Mixing (RAM) technique was used to mix the acidic solution with the powder.

The pultrusion process with both E-glass and carbon fiber reinforcement was developed at Composites Support and Solutions Inc (Colorado et al., 2010c). Composite Wo-CBPCs reinforced samples were fabricated with 15 volume \% of fibers. The die-temperature was $110^{\circ} \mathrm{C}\left(230^{\circ} \mathrm{F}\right)$ and the pull speed was $30.5 \mathrm{~cm} / \mathrm{min}(1 \mathrm{ft} / \mathrm{min})$. Wo-CBPC, pultruded WoCBPC with glass fibers and pultruded Wo-CBPC with carbon fiber samples were tested in three point bending tests. or each type of sample, three specimens were tested through the three point bending test. These tests were performed on an Instron 4411 at a crosshead speed of $2.5 \mathrm{~mm} / \mathrm{min}$. A Teflon mold was used for the fabrication of the CBPC samples that were not pultruded, which was then covered with plastic foil to preserve humidity and minimize the shrinkage effects. Samples were released after 48 hours and then dried at room temperature in open air for 5 days. Pultruded samples were made in a metallic die as shown in Fig. 12a. All samples were kept in a furnace at $50^{\circ} \mathrm{C}$ for 48 hours, to stabilize the weight loss at similar values than those obtained for long times at $20^{\circ} \mathrm{C}$. Fig. $12 \mathrm{a}$ shows the pultruded glass and carbon fiber composites with Wo-CBPC matrix fabricated with the die shown in Fig. 12a.

Fig. 13 shows cross section view images of the products shown in Fig. 12b. 


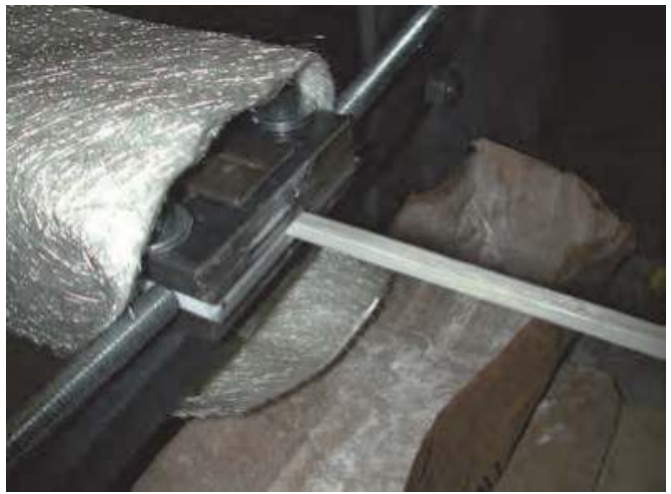

a)

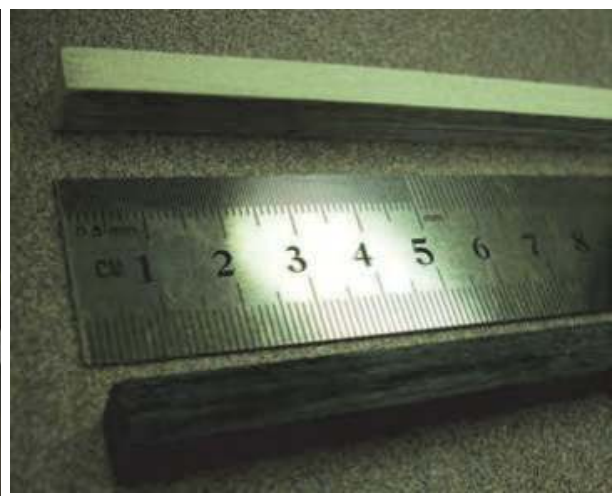

b)

Fig. 12. a) Pultrusion die during manufacturing of Wo-CBPCs reinforced with glass fibers, b) pultruded bars of Wo-CBPCs reinforced with glass fibers (white) and with carbon fibers (black)

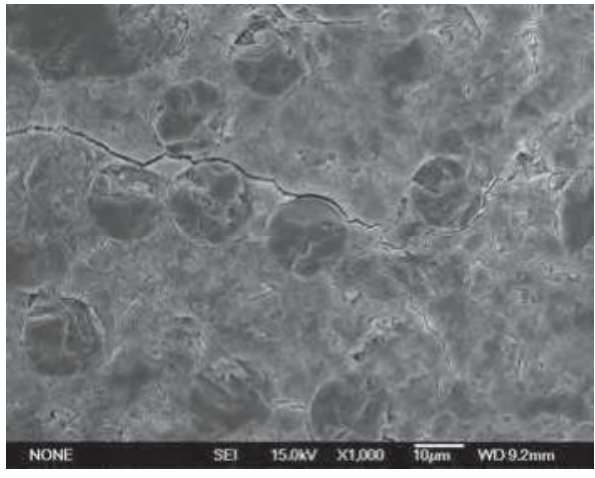

a

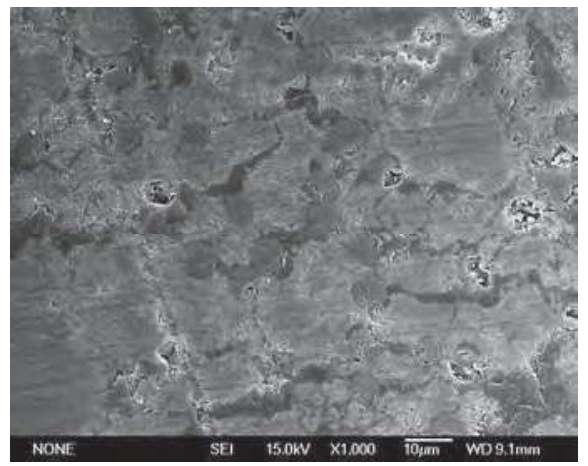

C

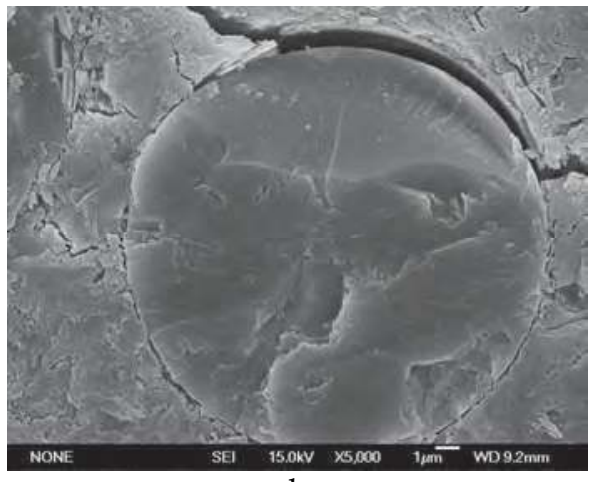

$\mathrm{b}$

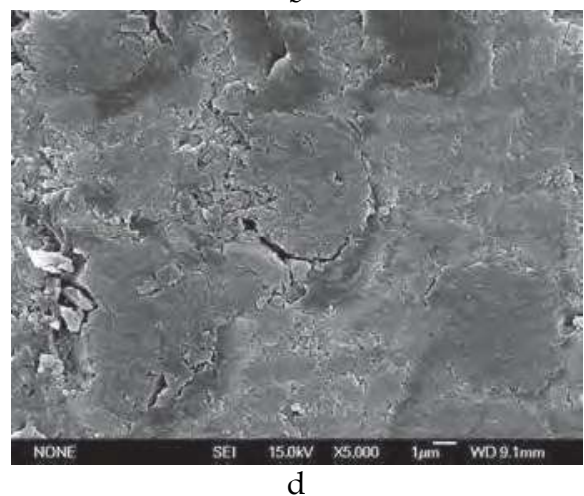

Fig. 13. SEM Cross section view images for Wo-CBPCs reinforced with a) and b) glass fibers; c) and d) carbon fibers; e) and f) basalt fibers; g) and h) $\mathrm{SiC}$ fibers. 
Fig. 13a and $b$ show the CBPC with glass fibers. Fig. 13a shows fibers homogeneously distributed and Fig. 13b, a magnification of Fig. 13a, shows CBPC fully impregnating the fibers. However, glass fibers appear almost debonded. Also, some cracks growing through the matrix and fiber-matrix interfaces.

On the other hand, Fig. 13c and d show the CBPC with carbon fibers. Fig. 13c is a cross section view image of the CBPC reinforced showing the carbon fibers homogeneusly distributed and a good matrix impregnation to fibers. Unlike the glass fibers reinforcement, debonding between the fiber and the matrix was not observed.. It is better shown by Fig. 13d, a magnification of Fig. 13c, which shows four fibers. Through whole sample, no cracks appear in matrix and matrix-fiber interfaces as well.

Fig. 14a and $\mathrm{b}$ show representation overviews of the pultruded glass fiber- and pultruded carbon fiber-reinforced chemically bonded phosphate ceramics respectively. The main difference between these two systems is basically the absence of interfacial cracks in the composite with carbon fibers.

Typical curves for the three point bending strength obtained for the Wo-CBPC pultruded fiber composites are presented in Fig. 16.

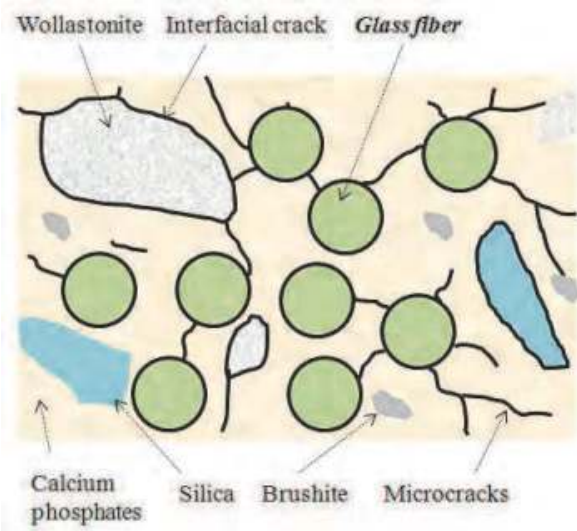

a

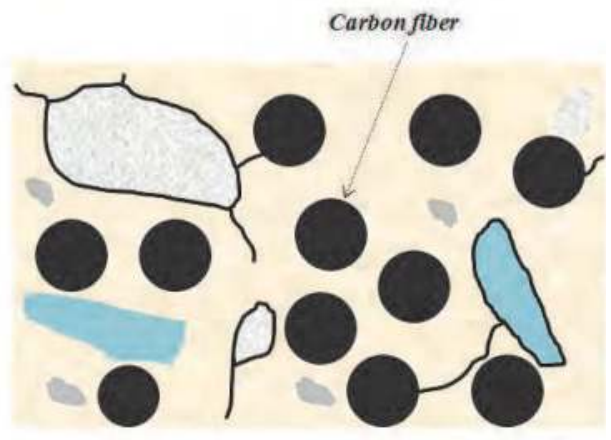

b

Fig. 14. Cross section view representation of the Wo-CBPCs a) reinforced with glass fibers, b)reinforced with carbon fibers

\section{Composite applications for Wo-CBPCs}

CBCs have been extensively used for multiple applications. They include: dental materials (Chow \& Eanes, 2001), bone tissue engineering (Barinov \& Komlev, 2008), shielding gamma and neutron radiation, nuclear waste solidification and encapsulation (Singh et al., 2000; Wagh, 2004, Chattopadhyay, 2003), electronic materials (Young \& Dimitry, 1990), tooling for advanced composites (Miller \& Wise, 1990), high temperature (Colorado et al., 2010a; Gulgun et al., 1994), composites with fillers and reinforcements (Wagh, 2004; Colorado et al., 2010a, 2010b, 2010c; Colorado et al., 2011). Above have been shown some of the Wo-CBPCs composites fabricated with GNPs and fiber reinforcements. Other structural applications involving high temperatures are the fire wall structures fabricated from Wo-CBPCs reinforced with different fibers. These are shown in Fig. 17. Electrical transformers are 
expensive equipments usually installed in groups with short space in between. If fire starts in one, it can be easily transferred to the other in a chain reaction. Wo-CBPCs have been successfully applied as a protection from fire in this case. In addition, because of the curing can be easily reduced to short periods and they are fabricated as cements, in situ fabrication and repair is also commercially feasible.

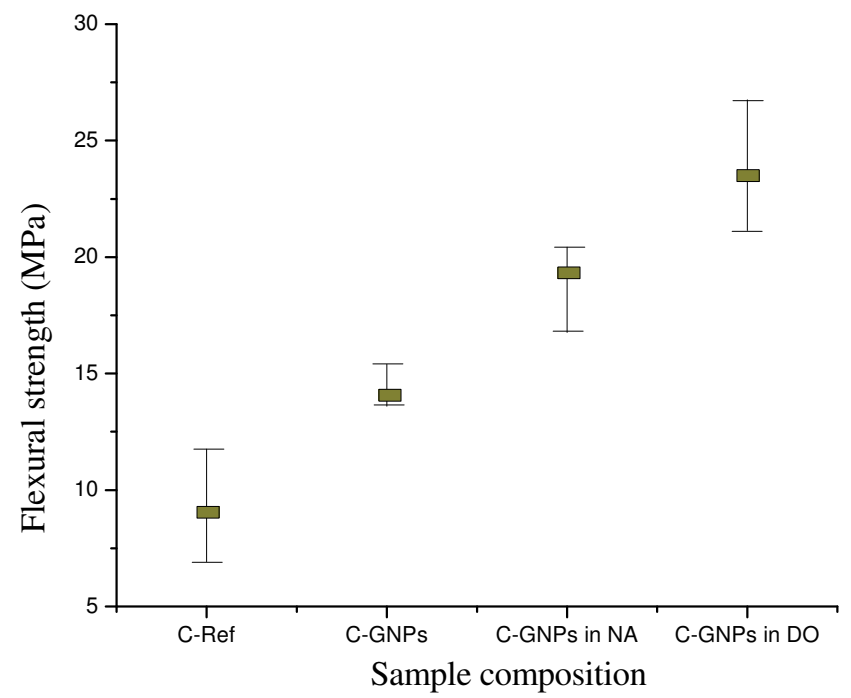

Fig. 15. Flexural strentgh results for the Wo-CBPCs pultruded fiber glass and graphite composites

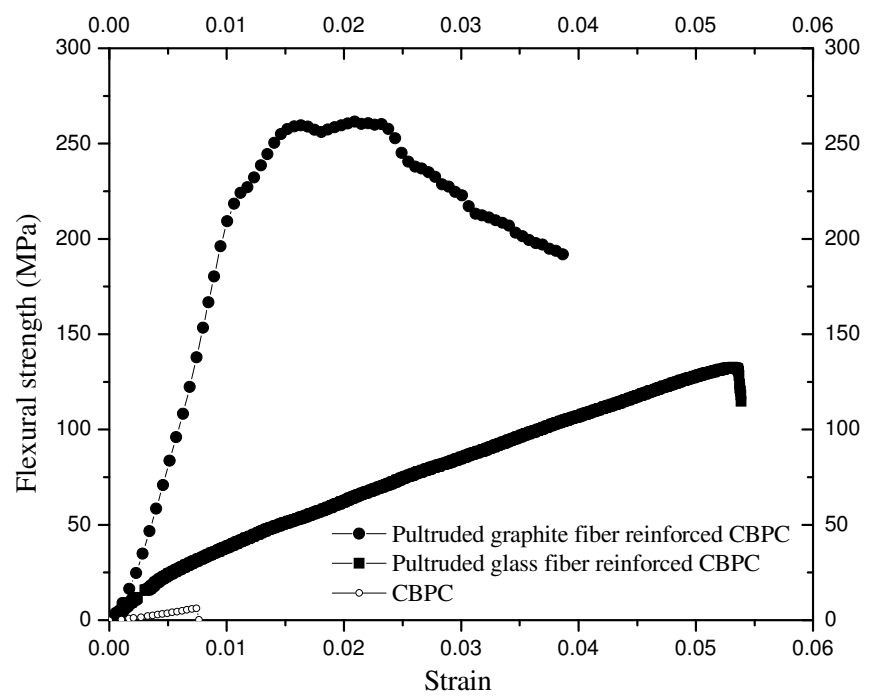

Fig. 16. Three point bending tests for pultruded Wo-CBPC with glass and carbon fibers 


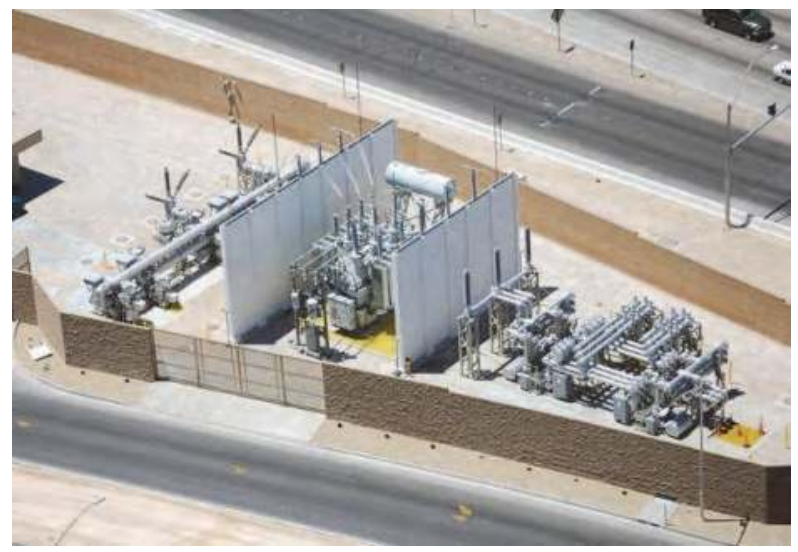

a

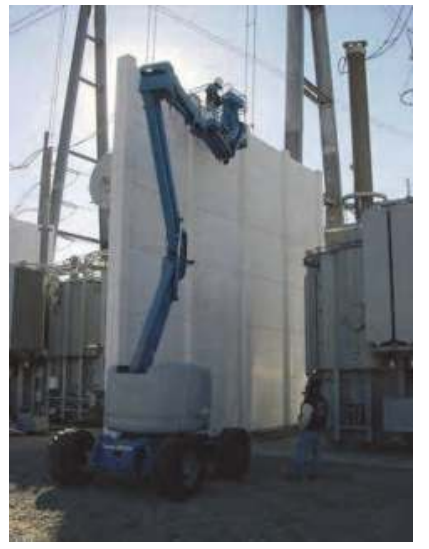

$\mathrm{b}$

Fig. 17. Composites fabricated from Wo-CBPCs, a) firewalls made of CBPCs composite panels reinforced with fibers for protection of electric transformers, $b$ ) detail of the panels installation.

Wo-CBPCs have also shown good adhesion properties with wood products and other ceramics and cements. This opens up the spectrum of applications for Wo-CBPC as structual materials like fire resistant houses or other wood-based constructions.

\section{Summary}

An overview of Wo-CBPCs composite materials have been presented in this chapter. Their formation, materials and main parameters controlling their manufacturing have been discussed. Also, it has been shown that Wo-CBPCs are composite materials itself with several crystalline (Wollastonite and Brushite) and amorphous phases (silica and amorphous calcium phosphates). Particle size distribution and Wollastonite age has a big impact in both setting time and compressive strength. Finally, progress in applications such Wo-CBPCs reinforced with graphite nanoplatelets and Wo-CBPCs with both carbon and glass fibers fabricated by a pultrusion process has been presented. These applications, in addition to all the advantages that CBPCs have with respect to traditional ceramics and cements, make possible Wo-CBPC as an ultimate material for structural applications.

\section{Acknowledgment}

The authors wish to thank to the NIST-ATP Program through a grant to Composites and Solutions Inc. (Program Monitor Dr. Felix H. Wu) and to Colciencias from Colombia for the grant to Henry A. Colorado.

\section{References}

Barinov, S. and Komlev, V. (2008). Calcium Phosphate based bioceramics for bone tissue engineering. Trans Tech Publications Ltd, Switzerland.

Chattopadhyay, S. (2003). Evaluation of chemically bonded phosphate ceramics for mercury stabilization of a mixed synthetic waste. National Risk Management Research Lab. Cincinnati, Ohio. 
Chow, L. C. and Eanes, E. D. (2001). Octacalcium phosphate. Monographs in oral science, vol 18. Karger, Switzerland.

Colorado, H. A.; Hiel, C. and Hahn, H. T. (2010a). Chemically bonded phosphate ceramic composites under thermal shock and high temperature conditions. Society for the Advancement of Material and Process Engineering, May 17-20, 2010. Seattle, Washington USA.

Colorado, H. A.; Hiel, C. and Hahn, H. T. (2010b). Influence of Particle Size Distribution of Wollastonite on the Mechanical Properties of CBPC's (Chemically Bonded Phosphate Ceramics). Materials Science \& Technology, Conference and Exhibition. October 17-21 in Houston, Texas USA. Ceramics Transactions.

Colorado, H. A.; Hiel, C. and Hahn, H. T. (2010c). Pultrusion of glass and carbon fibers reinforced Chemically Bonded Phosphate Ceramics. Journal of Composites Materials. In printing.

Colorado, H. A.; Hiel, C. and Hahn, H. T. (2011). Chemically bonded phosphate ceramics composites reinforced with graphite nanoplatelets. Composites: Part A, 42, 376-384.

Della Roy, M. (1987). New Strong Cement Materials: Chemically Bonded Ceramics, Science, Vol. 235: 651-58.

EPA. (2005). Compilation of Air Pollutant Emission Factors, Volume 1: Stationary Point and Area Sources, AP-42, Fifth Edition, U.S. Environmental Protection Agency, Office of Air Quality Planning and Standards, Research Triangle Park, North Carolina, January, 1995.

Gulgun, M. A.; Johnson, B. R. and Kriven, W. M. (1994). Chemically bonded ceramics as an alternative to high temperature composite processing. Mat. Res. Soc. Symp. Proc. Vol. 346. Materials Research Society.

Jeong, S. Y. and Wagh A. S. (2002). Chemical bonding phosphate ceramics: cementing the gap between ceramics, cements, and polymers, Argonne National Laboratory report.

Miller, L. and Wise, S. (1990). Chemical bonded ceramic tooling for advanced composites. Materials and Manufacturing Processes, Volume 5, Issue 2, 229-252.

Mosselmans, G.; Monique, B.; Willem, R.; Wastiels, J.; Leermakers, M.; Rahier, H.; Brughmans, S.; and Van Mele, B. (2007). Journal of Thermal Analysis and Calorimetry Vol. 883723 .

Singh, D.; Jeong, S. Y.; Dwyer, K. and Abesadze, T. (2000). Ceramicrete: a novel ceramic packaging system for spent-fuel transport and storage. Argonne National Laboratory. Proceedings of Waste Management 2K Conference, Tucson, AZ.

Wagh, A. S. (2004). Chemical bonded phosphate ceramics, Elsevier, Argonne National Laboratory, 283. ISBN: 0-08-044505-5, USA.

Wagh A. S. and Jeong, S. Y. (2003a). Chemically bonded phosphate ceramics: I, a dissolution model of formation, J. Am. Ceram. Soc., 86 (11): 1838-44

Wagh A. S. and Jeong, S. Y. (2003b). Chemically bonded phosphate ceramics: II, warmtemperature process for alumina ceramics, J. Am. Ceram. Soc., 86 (11): 1845-49.

Wagh A. S. and Jeong, S. Y. (2003c). Chemically bonded phosphate ceramics: III, reduction mechanism and its application to iron phosphate ceramics, J. Am. Ceram. Soc., 86 (11): 1850-55.

Wilson, A. D. and Nicholson, J. W. (1993). Acid based cements: their biomedical and industrial applications. Cambridge, England, Cambridge University Press.

Young, J. F. and Dimitry, S. (1990). Electrical properties of chemical bonded ceramic insulators. J. Am. Ceram. Soc., 73 [9] 2775-78. 


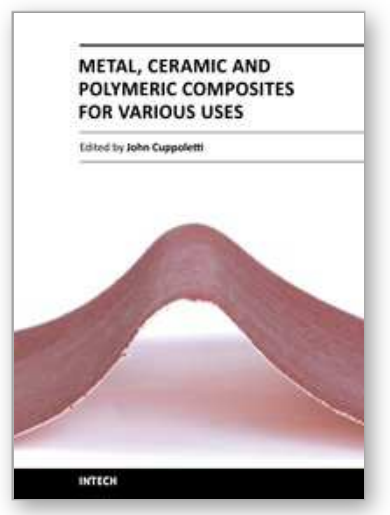

\author{
Metal, Ceramic and Polymeric Composites for Various Uses \\ Edited by Dr. John Cuppoletti
}

ISBN 978-953-307-353-8

Hard cover, 684 pages

Publisher InTech

Published online 20, July, 2011

Published in print edition July, 2011

Composite materials, often shortened to composites, are engineered or naturally occurring materials made from two or more constituent materials with significantly different physical or chemical properties which remain separate and distinct at the macroscopic or microscopic scale within the finished structure. The aim of this book is to provide comprehensive reference and text on composite materials and structures. This book will cover aspects of design, production, manufacturing, exploitation and maintenance of composite materials. The scope of the book covers scientific, technological and practical concepts concerning research, development and realization of composites.

\title{
How to reference
}

In order to correctly reference this scholarly work, feel free to copy and paste the following:

Henry Colorado, Clem Hiel, H. Thomas Hahn and Jenn-Ming Yang (2011). Chemically Bonded Phosphate Ceramic Composites, Metal, Ceramic and Polymeric Composites for Various Uses, Dr. John Cuppoletti (Ed.), ISBN: 978-953-307-353-8, InTech, Available from: http://www.intechopen.com/books/metal-ceramic-andpolymeric-composites-for-various-uses/chemically-bonded-phosphate-ceramic-composites

\section{INTECH}

open science | open minds

\section{InTech Europe}

University Campus STeP Ri Slavka Krautzeka 83/A 51000 Rijeka, Croatia Phone: +385 (51) 770447

Fax: +385 (51) 686166 www.intechopen.com

\section{InTech China}

Unit 405, Office Block, Hotel Equatorial Shanghai No.65, Yan An Road (West), Shanghai, 200040, China 中国上海市延安西路65号上海国际贵都大饭店办公楼 405 单元 Phone: +86-21-62489820

Fax: +86-21-62489821 
(C) 2011 The Author(s). Licensee IntechOpen. This chapter is distributed under the terms of the Creative Commons Attribution-NonCommercialShareAlike-3.0 License, which permits use, distribution and reproduction for non-commercial purposes, provided the original is properly cited and derivative works building on this content are distributed under the same license. 